children with sickle cell disease. The secondary aim is to analyse whether there is an association in children with sickle cell disease between health-related quality of life and 1) patient's age, 2) disease severity, and 3) caregiver's sociodemographic characteristics.

A retrospective cross-sectional evaluation of TNO-AZL Preschool Children Quality of Life questionnaire (TAPQOL, 0-1 year) and Pediatric Quality of Life Inventory ${ }^{\mathrm{TM}}$ (PedsQL $^{\mathrm{TM}}, 2-7$ years) data was conducted in children aged 0-7 years, living in the Netherlands. Study participants included caregivers of children with sickle cell disease referred for clinical follow-up at the sickle cell comprehensive care centres at Amsterdam UMC and Erasmus MC Rotterdam between April 2012 and October 2020. Clinical data were obtained from medical records record abstraction. Comparisons were made with previously published normative data on health-related quality of life in the general paediatric population, living in the Netherlands.

The study enrolled 136 caregivers of 136 children. On domains where significant differences existed between children with sickle cell disease and the general paediatric population, children with sickle cell disease scored lower with the most extensive impairment in children aged 5-7 years.

Multiple regression models showed a significant negative association between age and health-related quality of life. No association was found between health-related quality of life and disease severity or health-related quality of life and sociodemographic characteristics.

This study has demonstrated that health-related quality of life declines with age in very young children with sickle cell disease, with an extensive impaired health-related quality of life from 5 years of age when compared to the general paediatric population. This underlines the importance of the identification of high-risk patients with significantly impaired healthrelated quality of life as early in life as possible, to apply appropriate interventions for quality of life improvement. Future research should focus on factors influencing healthrelated quality of life in children with sickle cell disease.

\section{SARS-COV-2 INFECTION IN PEDIATRIC ONCOLOGICAL PATIENTS - OUR EXPERIENCE}

Aleksandra Bonevski*, Jasna Leniček Krleža, Jasminka Stepan Giljević, Nuša Matijašić, Maja Pavlović, Nada Rajačić, Filip Jadrijević Cvrlje, Izabela Kranječec, Renata Zrinski Topić. Children's Hospital Zagreb

10.1136/archdischild-2021-europaediatrics.313

The goal of the study was to present patients' demographic characteristics and clinical course of SARS-CoV-2 infection in children with malignancies treated at our Department. Additional goals were to evaluate the impact of infection on the course of diagnosis, treatment and/or follow up of the primary malignant disease and to determine anti-SARS-CoV-2 antibodies by quantitative assay after recovery from infection.

The study's participants were oncological patients, treated and monitored at our Department, who developed SARS-CoV2 infection. Demographic data, symptoms and the impact of infection on diagnosis, treatment and/or follow up of the primary disease were collected from questionnaires, filled by patients' parents, in the presence of a medical doctor. Patients and their parents were informed about the study's concept, and all signed consent forms before data and sample collection took place. Laboratory tests (total proteins, albumins, A, M, G immunoglobulin classes) as well as anti-SARSCoV-2 antibodies were done at Department of Medical Biochemistry of the Children's Hospital Zagreb.

At the time of writing this abstract we have collected complete data on 14 patients, 9 boys. Primary diagnoses were: ALL (5), Wilms tumor (3), Hodgkin's lymphoma (2), rhabdomyosarcoma (2), desmoplastic infantile ganglioglioma (1) and yolk sack tumor (1). Three patients were diagnosed with SARS-CoV-2 infection during intensive treatment, 2 at initial presentation of primary disease, 4 during maintenance treatment, and 5 during follow up. All the participants, except one patient who was initially treated at another hospital and had underwent only rapid antigen test, had positive RT-PCR test. The common most symptom was fever (9), followed by rhinorrhea (5), loss of appetite (4), cough (2), dyspnoea (2), loss of taste/smell (2), sore throat (1), lethargy (1), vomiting (1), diarrhea (1) and abdominal pain (1). None of the patients developed multisystemic inflammatory syndrome. Four patients had asymptomatic infection. Serology test was done 2.5-4.5 months post-infection, and was positive in 10 patients, while 1 patient had values just below the cut off limit $(0.8 \mathrm{U} / \mathrm{mL})$. Out of 9 patients infected during the treatment (initiation, intensive or maintenance treatment), 5 reported short postponement in oncological therapy, and none had delay in crucial diagnostics.

Our study is still ongoing, but according to the results so far, none of our patients developed severe clinical presentation of SARS-CoV-2 infections, and the infection itself did not interfere much with oncological treatment.

Majority of patients developed detectable anti-SARS-CoV-2 antibodies.

\section{VITAMIN D SUPPLY FOR CHILDREN AND ADOLESCENTS WITH CANCER IN THE SOUTH OF RUSSIA}

Svetlana Dolbnya*, Alice Karaseva, Viktoriya Kur'yaninova, Inna Stremenkova, Leonid Klimov. Stavropol State Medical University, Stavropol 355017, Russian Federation

10.1136/archdischild-2021-europaediatrics.314

Study Objective To assess the supply of vitamin D in children and adolescents with cancer in the Stavropol Territory $\left(45^{\circ}\right.$ north latitude).

We examined 36 children with cancer (18 boys and 18 girls). There were 11 children (30.6\%) aged from 0 to 3 years, $16(44.4 \%)$ - from 4 to 10 years, 9 (25.0\%) children from 11 to 18 years. The average age is $7.9 \pm 0.9$ years.

Leukemia was revealed in $19(52.8 \%)$ children, solid tumors - in 9 (25.0\%), lymphomas - in 8 (22.2\%) children.

The median calcidiol level was 17.5 [12.6-23.4] ng/ml. A deficiency of vitamin $\mathrm{D}$ (less than $20 \mathrm{ng} / \mathrm{ml}$ ) was detected in $21(58.3 \%)$ children, a deficiency at the level of $20-30 \mathrm{ng} / \mathrm{ml}$ - in $10(27.7 \%)$, a level of more than $30 \mathrm{ng} / \mathrm{ml} \mathrm{-} \mathrm{in} 5(13$, 9\%) of examined children.

Median $25(\mathrm{OH})$ D in children with leukemia was 21.2 [14.6-22.4] ng/ml, with solid tumors - 16.2 [9.3-16.4] ng/ml, with lymphomas - 15.8 [11.7-22.8] ng/ml. Nine (47.4\%) children with leukemia, $7(77.8 \%)$ with solid tumors and 5 $(62.5 \%)$ with lymphomas had a serum calcidiol level of less than $20 \mathrm{ng} / \mathrm{ml}$, deficiency of $20-30 \mathrm{ng} / \mathrm{ml}$ was detected in 6 (31.6\%), $1(11.1 \%)$ and $3(37.5 \%)$ children, respectively, the level of more than $30 \mathrm{ng} / \mathrm{ml}$ was detected in $4(21.0 \%)$ 
children with leukemia and $1(11.1 \%)$ of a patient with a solid tumor.

The median vitamin $\mathrm{D}$ supply in children from 0 to 3 years old was 16.6 [9.7-21.7] $\mathrm{ng} / \mathrm{ml}$, from 4 to 10 years old - 19.8 [14.7-24.8] ng/ml, from 11 to 18 years old - 16.8 [10.5-17.2] ng/ml. Vitamin D deficiency (less than $20 \mathrm{ng} / \mathrm{ml}$ ) was detected in $6(54.6 \%)$ children under 4 years old, in 8 (50.0\%) children from 4-10 years old and 7 (77.8\%) adolescents of 11 years old and older $(\mathrm{p}<0.05)$; insufficiency with the level from 20 to $30 \mathrm{ng} / \mathrm{ml}$ was detected in $3(27.3 \%), 6$ $(37.5 \%)$ and $1(11.1 \%)$ children, and the level of more than $30 \mathrm{ng} / \mathrm{ml}$ was found in $2(18.1 \%), 2(12.5 \%)$ and $1(11.1 \%)$ children, respectively.

Conclusions in the south of Russia, the majority $(86.0 \%)$ of children and adolescents with cancer have a $25(\mathrm{OH})$ D level of less than $30 \mathrm{ng} / \mathrm{ml}$. Level of $25(\mathrm{OH})$ D did not significantly depend on the type of cancer. Adolescents with cancer are at risk for vitamin D deficiency (less than $20 \mathrm{ng} / \mathrm{ml}$ ).

\section{INTEGRATING SAFFRON METABOLOMICS INTO THE TREATMENT OF PEDIATRIC CANCERS}

Kyriaki Hatziagapiou*, Olti Nikola, Eleni Kakouri, George Lambrou, Eleni Koniari, Christina Kanaka-Gantenbein, Petros Tarantilis. National and Kapodistrian University of Athens, First Department of Pediatrics, Choremeio Research Laboratory, 'Aghia Sophia' Children's Hospital, Athens, Greece

\subsection{6/archdischild-2021-europaediatrics.315}

Natural plant extracts are an important source of antitumor agents, and still provide promising approaches for discovering new drugs. Crocus sativus (saffron) is endowed with anticancer, differentiating, antioxidant and genoprotective properties. Its pharmacological properties are attributed to biologically active substances, crocins (CRCs) which are hydrophilic carotenoids. They are glycosy-esters of the amphiphilic natural carotenoid crocetin (CRT), which exhibits extensive distribution and penetration through lipid bilayers. The hemisynthetic derivate dimethylcrocetin (DMCRT) is similar to CRT and is soluble in many organic solvents. With regards to safety, saffron and its constituents are considered practically non-toxic substances. The current research aims to study the in vitro cytotoxic effect of the natural carotenoids CRCs and DMCRT on a medulloblastoma cell line.

CRCs are diluted to nuclease and protease free water and DMCRT to $10 \%$ DMSO.

For the biological assays TE-671 medulloblastoma cells are incubated in 96-well plates at a range of concentrations of CRCs $(0.18-22.85 \mathrm{mg} / \mathrm{ml})$ and DMCRT $(0.18-11.43 \mathrm{mg} / \mathrm{ml})$ for 24, 48 and 72 hours. Analysis of cell viability is performed with Alamar Blue and MTT viability assays.

CRCs manifest a cytotoxic effect in a dose and timedependent manner $(p<0.001$ for exposed cells to any concentration at 24, 48 and 72 hours versus cells not exposed); as their concentration increases, cell viability is reduced for all time points. For the same concentration, as the time of exposure increases, the inhibitory effect is increased. The antiproliferative effect of DMCRT is less pronounced, observed only at concentrations higher than $5.71 \mathrm{mg} / \mathrm{ml}$ at 24 and 48 hours and higher than

$1.43 \mathrm{mg} / \mathrm{ml}$ at 72 hours, whereas for lower concentrations the effect is not statistically significant. IC50 values for each time point are calculated as $3.230,2.14$ and $1.72 \mathrm{mg} / \mathrm{ml}$ for
CRCs and 5.9, 5.6 and $3.712 \mathrm{mg} / \mathrm{ml}$ for DMCRT at 24, 48, and 72 hours, respectively.

The results of our study could afford the basis of research, regarding the use of natural carotenoids as an alternative solution to the toxicity of retinoids, especially for the vulnerable pediatric population and during pregnancy, while retaining the anticancer properties of retinoids.

Acknowledgements The research is co-financed through the Program 'Support for researchers with an emphasis on young researchers-cycle B ' (MIS 5048464) AND The Foundation for Education and European Culture (IPEP).

\section{INTEGRATING NON PSYCHOACTIVE PHYTOCANNABINOIDS AND THEIR CYCLODEXTRIN INCLUSION COMPLEXES INTO THE TREATMENT OF NEUROBLASTOMA}

Kyriaki Hatziagapiou*, Konstantinos Bethanis, Olti Nikola, Elias Christoforides, Eleni Koniari, Eleni Kakouri, George Lambrou, Christina Kanaka-Gantenbein. National and Kapodistrian University of Athens, First Department of Pediatrics, Choremeio Research Laboratory, 'Aghia Sophia' Children's Hospital, Athens, Greece

\subsection{6/archdischild-2021-europaediatrics.316}

The non-psychotropic cannabidiol (CBD), deriving from Cannabis sativa is endowed with anticancer, antioxidant and genoprotective properties, which along with its safe profile suggest it as a promising approach in cancer therapy. The low solubility of CBD hampers its therapeutic potential.

Cyclodextrins (CDs) are cyclic oligosaccharides used in pharmaceutical industry to incorporate apolar molecules inside their hydrophobic cavity, increasing their stability, water solubility and bioavailability.

CBD-inclusion complexes with CDs are a good nanomedicine-based formulation strategy to improve CBD's properties. The current research aims to study the potential cytotoxic effect of CBD and CBD-CDs complexes CBD-RMßCD (randomly methylated $\beta$-cyclodextrin) and CBD-HP $\beta C D$ (hydroxypropyl-b-CD) on neuroblastoma cells.

CBD is diluted in 10\% DMSO and CBD/CDs solutions are prepared by mixing solid $\mathrm{CBD}$, solid $\mathrm{CDs}$ and $\mathrm{dH} 2 \mathrm{O}$. Phase solubility studies are conducted to determine improvement in CBD's solubility from CDs' addition of. For the biological assays SH-SY5Y and BE(2)-M17 neuroblastoma cells are incubated at a range of concentrations $(0,03125-4 \mathrm{mg} / \mathrm{ml})$ of CBD, CBD-RM $\beta C D$, CBD-HP $\beta C D, R M \beta C D$ and $H P \beta C D$ for 24, 48 and 72 hours. Analysis of cell viability is performed with Alamar Blue viability assay.

CBD's solubility is enhanced in the presence of both CDs. $\mathrm{CBD}$ and all $\mathrm{CBD} / \mathrm{CD}$ s exert significant cytotoxicity in a dose and time-dependent manner; as their concentration and time of exposure increase, cell viability is reduced. The cytotoxic effect is more pronounced in cells exposed to CBD-HP $\beta C D$ for all concentrations and time-points. RM $\beta C D$ and HPßCD at the highest concentration of $4 \mathrm{mg} / \mathrm{ml}$ exert antitumor action per se. IC50 values are calculated as $0.29,0.21,0.06$ $\mathrm{mg} / \mathrm{ml}$ for CBD, $0.046,0.035,0.03 \mathrm{mg} / \mathrm{ml}$ for CBD-RM $\beta C D$, and $0.029,0.023,0.021 \mathrm{mg} / \mathrm{ml}$ for CBD-HPßCD at 24, 48, and 72 hours, respectively for SHSY5Y cells. For BE(2)-M17 cells IC50 values are $0.3,0.27,0.19 \mathrm{mg} / \mathrm{ml}$ for CBD, 0.1655, $0.1644,0.1534 \mathrm{mg} / \mathrm{ml}$ for CBD-RMßCD, and 0.1086 , $0.1020,0.071$ for CBD-HPßCD at 24, 48, and 72 hours, respectively. 